\title{
For the Patient
}

The full report is titled "A comparison of seasonal trends in asthma exacerbations among children from geographic regions with different climates." It is in the November-December 2016 issue of the Allergy Asthma Proceedings (volume 37, pages 475 to 481). The authors are Wisniewski JA, McLaughlin AP, Stenger PJ, Patrie J, Brown MA, El-Dahr JM, Platts-Mills TAE, Byrd NJ, and Heymann PW.

For the Patient is provided to physicians so that the patients can better understand the language of modern medicine.

For the Patient is written by the editors (Bellanti JA, and Settipane RA) and provided to practitioners so that patients can better understand the usefulness of new information that results from medical research.

For the Patient is intended for informational purposes only. This educational synopsis is not meant as a substitute for medical advice. If you have questions regarding this material or are in need of medical advice, please contact your physician. Reproduction is limited to notfor-profit educational purposes only. All other reproductions must be approved by OceanSide Publications.

\section{Seasonal trends in asthma exacerbations among children from different geographic regions}

Although it is known that asthma can show clinical seasonal fluctuations, especially in areas with a temperate climate, the fall season peak in childhood asthma exacerbations is commonly thought to be related to an increase in viral infections and allergen exposure when children return to school. Whether or not the seasonality of asthma attacks among children from different geographic regions follows similar trends is unclear. In a recent study, Dr. Wisniewski and associates postulated that seasonal patterns for hospital admissions as well as emergency department visits for asthma exacerbations would differ among school-age children who live in locations with different climates and that these differences could have important therapeutic implications.

\section{Who or What Was Proposed to Be Studied?}

Hospital billing data bases were examined to determine the number of patients who were hospitalized or treated in the emergency department monthly for asthma exacerbations among school-age children who lived in four geographic U.S. areas, which included Charlottesville, Virginia, Tucson, Arizona, Yuma, Arizona, and New Orleans, Louisiana.

\section{How Was the Study Done?}

Data from the four cities within three states were compared with climate data obtained from the archives of the National Climate Data Center, U.S. Department of Commerce.

\section{What Are the Limitations of the Proposed Study?}

Because this was a retrospective pilot study, the results were subject to recall bias and by being a small sample size.

\section{What Are the Implications of the Study?}

The results of this study supported the hypothesis and indicated that, although rhinovirus infections are important factors in initiating asthma attacks in children, exposure to other environmental aeroallergens at the time of a rhinovirus infection is likely to contribute significantly to seasonal peaks in asthma exacerbations, which vary geographically. The use of local geographic information to recognize seasonal changes in the frequency of asthma exacerbations, together with individual patient risk factors (e.g., allergic sensitizations), should enhance efforts to optimize the treatment of children with asthma during periods when they are most likely to experience an attack. 